\title{
A Cross-Sectional Analysis of Mathematics Education Practices at Canadian Universities
}

Chester Weatherby

Wilfrid Laurier University

Donna Kotsopoulos

Huron University College

Douglas Woolford

Western University

Laaraib Khattak

University of Waterloo

\begin{abstract}
In response to international standardized testing, many countries are examining mathematics education at virtually every level of instruction. Canada is no exception. Declines in mathematics scores in some international standardized tests have raised concerns amongst some stakeholders that a crisis may be unfolding with respect to the readiness of students to study mathematics in university. These results raise questions about the ways in which students are streamed into university mathematics and the supports provided once they begin their studies. Our focus in this research was university-level mathematics education. To mimic how students, parents, counselors, and others are most likely to find information about mathematics programs and support, we engaged in a web-based examination of departments of mathematics at 62 Canadian universities. Our objectives were to examine the types of degrees offered, admission protocols (including types of streaming or placement tests), methods for remedial support, accessibility of online information, mathematics help centers, courses for non-mathematics majors, and access initiatives as a preliminary step in analyzing the broader Canadian landscape in post-secondary mathematics education. Our findings reveal remarkably consistent practices across Canadian institutions. A rethinking of practices may be necessary in order
\end{abstract}


to support those students that appear to be underprepared for post-secondary mathematics.

\section{Introduction}

International standardized tests of mathematics have resulted in an unprecedented focus for many countries worldwide on factors contributing to success across all levels of mathematics education. Canada is no exception. Canada's recent performance on various international standardized tests of mathematics has resulted in fierce debates about the extent to which a potential crisis is unfolding or even already underway (Alphonso, 2013; MacDonald, 2014; Sands, 2014).

Recent results from the Organization for Economic Co-operation and Development's (OECD) Programme for the International Assessment of Adult Competencies (PIAAC) test suggests that Canadians between the age of 16 and 65 have below average numeracy skills (Scerbina et al., 2013). Recent Programme for International Student Assessment (PISA) data shows a decline in mathematics scores in Canada amongst 15-year-olds (O'Grady, Deussing, Scerbina, Fung, \& Muhe, 2013). Considering the change over time using data from the 2003 International Adult Literacy and Skills Survey (IALSS), more Canadians are doing poorly in numeracy compared to a decade ago (Scerbina et al., 2013; Statistics Canada, 2005). To be clear, Canadians are performing well compared to many, if not most, other countries; however, scores have dropped and more countries are doing better than Canada.

The public debates on Canada's performance in mathematics on international standardized tests has resulted in more general concerns about the number of science, technology, engineering, and mathematics (STEM) based graduates Canada is producing and also the readiness of current and future students to study post-secondary mathematics (Conference Board of Canada, 2014; Ovsey, 2013). Recent discourse points to mathematical ability as a key driver of innovation and the economy (Moffatt \& Rasmussan, 2016). While the overall number of graduates from STEM fields has increased in all provinces over recent years, Canada continues to lag behind other countries in terms of graduates per capita (Conference Board of Canada, 2014). Moreover, there is an underrepresentation of women and Indigenous people (Conference Board of Canada, 2014; Hango, 2013a, 2013b). Given that STEM-based graduates have been found to have higher earning potential and increased likelihood of employment and job satisfaction, the underrepresentation of women and Indigenous people in post-secondary mathematics programs is particularly concerning.

Results from the United States point to high levels of students moving out of STEM-based disciplines altogether, with underperformance being a key contributing factor (Stinebrickner \& Stinebrickner, 2014). Based on institutional streaming placement test data, the Carnegie Foundation for the Advancement of Teaching suggests that approximately $75 \%$ of US college students are at least two or more levels behind in terms of their readiness to study mathematics (Silva \& White, 2013; Strother, Campen, \& Grunow, 2013). As a result, between $60-70 \%$ of students usually require at least one mathematics remediation course to be adequately prepared to study mathematics at the post-secondary level. These remediation programs can be costly for the 
student and the post-secondary sector more generally (Let's Talk Science, 2013; Strother et al., 2013).

Underperformance and lack of readiness may also be very real and concerns are mounting in Canada as well, given the national results on international standardized testing of mathematics. Based on our own experiences and based on informal discussions with colleagues across Canada, we hypothesize that many universities may be facing challenges with success in mathematics and particularly in first year mathematics. Data demonstrating this perspective would be challenging to obtain.

\section{Current Research}

Research focusing on Canadian university mathematics education is remarkably scant (Dion, 2014; Dooley, Payne, Steffler, \& Wagner, 2016). The research presented in this paper is part of a larger project exploring institutional-level factors (cf. individual class-level factors) that may affect students' success in university-level mathematics education specifically.

Two Canadian studies were found that took a broad perspective on the role of high school mathematics education and future post-secondary education choices. Dooley et al. (2016) analyzed factors that contributed to high school students continuing in STEM-based studies (broadly defined) during university. Their results indicated that later year high school mathematics and science courses heavily influenced a student's engagement in future STEM education, with success in science courses being the most significant predictor (Dooley et al., 2016). Nahornick (2016) also took a broad view in her comparison of mathematics prerequisites for general Bachelor of Arts and Bachelor of Science degrees. Her analysis revealed that nearly all Bachelor of Arts degrees reviewed did not require a mathematics prerequisite whereas $60 \%$ of Bachelor of Science degrees required one or less mathematics prerequisites. Our research focuses specifically on mathematics education and provides a more extensive analysis of university-level factors; therefore, our research contributes to this identified gap in research on the topic of post-secondary mathematics education participation and success.

In this paper, we report on a web-based analysis of 62 mathematics (or mathematics degree offering) departments at English-speaking Canadian universities. Our view is that the web is often the first source of information for students, parents, high school counselors, academic advisors, and so forth. University recruitment material is increasingly only available electronically for this very reason. We note up front that this may be viewed as a limitation of our study and that the practices and information we explore may be available in other formats. However, if such information is not available on the web, our view is that the support may be unknown by many, if it indeed does exist. The web is a crucial source of information and a relevant context for studying the types of information 21 st century students are receiving.

In our analysis, we document aspects of individual departmental differences such as publicly reported degree offerings, entrance averages, prerequisites, streaming protocols, remedial support, accessibility of online information, mathematics help centers, courses for nonmathematics majors, and special initiatives for underrepresented groups. Our objective is to 
characterize the extent to which practices at Canadian departments of mathematics differ and/or align with each other and the available research.

This research, while relatively straightforward, is nevertheless an important and necessary first step in constructing the Canadian landscape of post-secondary mathematics education. While the focus of this research is decidedly Canadian, the research will likely be of interest to any university, college, or department of mathematics who may be experiencing challenges in student success, enrolment, or both.

\section{Literature Review}

Only two large-scale studies of post-secondary mathematics education appear to explore studentand institutional-level factors contributing to success in post-secondary mathematics in Canada. First, some robust analysis in relation to success in college-level mathematics has occurred in the province of Ontario through the College Mathematics Project (Orpwood, Schollen, Leek, Marinelli-Henriques, \& Assiri, 2011). College-level post-secondary education in Canada usually implies applied programming resulting in diplomas or certificates and some limited baccalaureate degrees (cf. colleges in the United States). Data analyzed in the most recent iteration of this multiyear cross-sectional research found $67.6 \%$ of students achieved grades of A, B or C and $32.4 \%$ were considered to be at risk, where the latter refers to a student receiving a D, F, or withdrawing from the course. Arguably, those students receiving a grade of $\mathrm{C}$ may be equally at risk. Overall, students have consistently been found to be underprepared to study mathematics at the college level since the College Mathematics Project study began in 2007.

The second large-scale study - and perhaps the most comprehensive Canadian studyrelated to success factors in university mathematics education was conducted by Dame (2012) at the University of Victoria. Her study quantitatively evaluated factors contributing to student success in entry level (i.e., first year) mathematics courses. Using institutional data, surveys, and predictive modeling for an entire first-year cohort of students, Dame (2012) found that: (a) achievement in secondary level education mathematics was highly correlated with success in entry level mathematics; (b) students who did well in secondary school English also did well in postsecondary mathematics; (c) the institutional streaming (i.e., placement test) was found to be a poor measure of subsequent student success; (d) students who most needed remediation failed to take advantage of the resources due to lack of time or scheduling conflict; (e) students who struggled reported missing class more and doing less homework; and (f) many students were not adequately prepared for entry level mathematics courses, even though most of them met or exceeded the prerequirement for admission.

One key recommendation from Dame (2012) was that remediation should be built into students' academic programming rather than as an optional add-on. Other studies conducted in the United States to evaluate the effectiveness of remedial programs have also produced mixed results in terms of the supportiveness of such efforts (Hagedorn, Siadat, Fogel, Nora, \& Pascarella, 1999). Many of these studies also showed that remedial programs that are integrated into the degree requirements (i.e., co-requisites) of the students appeared to be more effective (Charles A. Dana 
Center, Complete College America Inc., Education Commission of the States, \& Jobs for the Future, 2012; Complete College America, 2012).

Dame's (2012) findings were consistent with other research that has shown some challenges faced by students are clearly at the student-level, such as attendance, socioeconomic status, homework completion, poor mathematics performance at the secondary level, anxiety, and the willingness to seek extra help through help centers or additional summer programming (Hagedorn et al., 1999; Mji \& Mwambakana, 2008; Perkin \& Bamforth, 2011). Dame's results were also consistent with other research that has examined efforts to stream students into courses based on placement tests; namely, such efforts tend to have very discrepant results and are likely to be more effective if locally developed as opposed to a standardized measure such as the Scholastic Aptitude Test (SAT) (Hailikari, Nevgi, \& Komulainen, 2008).

Dame's (2012) study did not explore gender or the participation of Indigenous peoples as variables. International standardized tests show that Canadian females underperform in mathematics compared to males at both the elementary and secondary school levels (Hall, 2012; Organisation for Economic Co-operation and Development, 2012; Scerbina et al., 2013). A recent study by Hall (2012) of culturally-similar countries (i.e., Canada, England, and Australia) found that males enrolled more in optional mathematics preparation courses than females prior to postsecondary education; consequently, some males may simply be more mathematically-ready for post-secondary education. While women outnumber men in most fields of study in Canada, this does not hold true for mathematics. If we take, for example, the University of Waterloo, which arguably hosts a significant proportion of all Canadian mathematics students, the proportion of female math students has historically been low (University of Waterloo, 2018). Based on institutional data, the proportion of females in undergraduate mathematics programs at the University of Waterloo has recently been between $31.6 \%$ (2008) and 35.4\% (2016). Other studies consider the related disciplines of mathematics and computer science together and indicate lower female enrollment compared to males (Conference Board of Canada, 2014; Ferguson, 2016; Hango, 2013a, 2013b; Statistics Canada, 2011). Mathematics and computer science may be grouped together because of similarly low enrolments. When considering female participation in STEM disciplines, in 2011 it was reported that women between the ages of 25 and 64 made up $33 \%$ of STEM degree graduates, noting the representation female students across age categories as 39\% for ages 25-34 and 23\% for women aged 55-64 (Ferguson, 2016; Statistics Canada, 2011). When focusing on mathematics and computer science graduates, women accounted for the proportions $30 \%$ and $29 \%$ for ages 25-34 and 55-64 respectively. Females with proven mathematical ability in secondary school still choose mathematics as a discipline in post-secondary education less than their male counterparts (Hango, 2013a). Mathematics and mathematical thinking and ability is the common thread between many of the STEM disciplines that see an underrepresentation by females.

The 2011 National Household Survey reports that less than 11\% of Indigenous peoples report having studied STEM-based disciplines, compared to $24 \%$ of non-Indigenous (Statistics Canada, 2011). Statistics Canada does not separate out graduate rates based on Indigenous status. Consequently, this information is unknown for STEM-based studies. More general data related to 
post-secondary participation rates suggest that Indigenous people represent fewer than 3\% of the total undergraduate population in Canada and "less than 8\% of Indigenous peoples ages 15-64 have a university credential" (Pidgeon, Archibald, \& Hawkey, 2014, p. 3). Consequently, it may be safe to assume that the numbers of Indigenous peoples enrolled in mathematics degrees may also be low.

Most universities offer some sort of remedial mathematics help for students—often in the form of mathematics help centers. Dietsche's (2012) study of Ontario college students' use of the services provided by mathematics help centers reported that although $34 \%$ of students responded that they would somewhat benefit from mathematics help centers, $87 \%$ of students reported nonuse of such services at their college. Interestingly, female students used the mathematics help services less frequently than males (Dietsche, 2012).

In response to high failure rates in post-secondary mathematics, Faridhan, Loch, and Walker (2013) examined the mathematical outcomes of students who take advantage of mathematics help centers. Similar to Dame's (2012) findings, they showed that students who take advantage of these services tend to perform better in their mathematics courses. This may be related to increased levels of personal engagement with the content and with others, since a student who finds a sense of belonging by means of actively connecting with staff, faculty members, and other students tends to be more successful in attaining their post-secondary objectives (Kuh, Kinzie, Buckley, Bridges, \& Hayek, 2007). Relationships that enable a sense of personal belonging and personal engagement have also been found to be particularly important to Indigenous students (Pidgeon et al., 2014). Consequently, investing in mathematics help centers and providing more access to these centers may be helpful for students.

\section{Methods}

\section{Participants}

Names of universities in Canada were retrieved from the website universitystudy.ca, which is an official Universities Canada database. We found 78 English-speaking and 19 Frenchspeaking universities in Canada. Unfortunately, French-speaking universities had to be removed from our survey due to the language limitations of the authors. All remaining English-speaking universities were further examined to determine whether or not they offered a mathematics degree. Institutions with a highly specialized focus and without a mathematics department or mathematics help center were then dropped from this list. We do not group universities by broad categories (e.g., student population, research profile, etc.). These categories can be constructed in a variety of ways and as such, our approach is to name universities so that readers can make comparisons applicable to their own particular needs. In total, 62 universities were included in our analysis. See Table 1 for a list of the universities included in the sample and Figure 1 for the breakdown of type of mathematics programs offered by these universities. 
Table 1

Universities Included in the Present Study

\begin{tabular}{ll}
\hline Universities & \\
\hline Acadia University & Saint Mary's University \\
Algoma University & Simon Fraser University \\
Athabasca University & St. Francis Xavier University \\
Bishop's University & Thompson Rivers University \\
Brandon University & Trent University \\
Brock University & Trinity College \\
Campion College & Trinity Western University \\
Canadian Mennonite University & University of Alberta \\
Cape Breton University & University of British Columbia \\
Carleton University & University of Calgary \\
Concordia University & University of the Fraser Valley \\
Concordia University of Edmonton & University of Guelph \\
Dalhousie University & University of Manitoba \\
King's College Halifax & University of New Brunswick \\
King's University College & University of Northern British Columbia \\
Kwantlen Polytechnic University & University of Ontario Institute of Technology \\
Lakehead University & University of Ottawa \\
Laurentian University & University of Prince Edward Island \\
Lethbridge University & University of Regina \\
Luthor College & University of Saskatchewan \\
MacEwan University & University of St. Michael's College \\
McGill University & University of Toronto \\
McMaster University & University of Victoria \\
Memorial University & University of Waterloo \\
Mount Allison University & University of Windsor \\
Mount Saint Vincent University & University of Winnipeg \\
Nipissing University & Vancouver Island University \\
Queen's University & Victoria University \\
Redeemer University College & Western University \\
Royal Military College & Wilfrid Laurier University \\
Ryerson University & York University \\
\hline &
\end{tabular}

\section{Data Sources}

Data were collected using the Internet over the months of September, October, and December of 2015. A web-based analysis was conducted to review mathematics departmental websites, related university web pages, and 2015-2016 course calendars. Any changes, additions, or deletions of programing or requirements at the institutions beyond this period are not reflected in this analysis. A second research assistant verified the data set. 


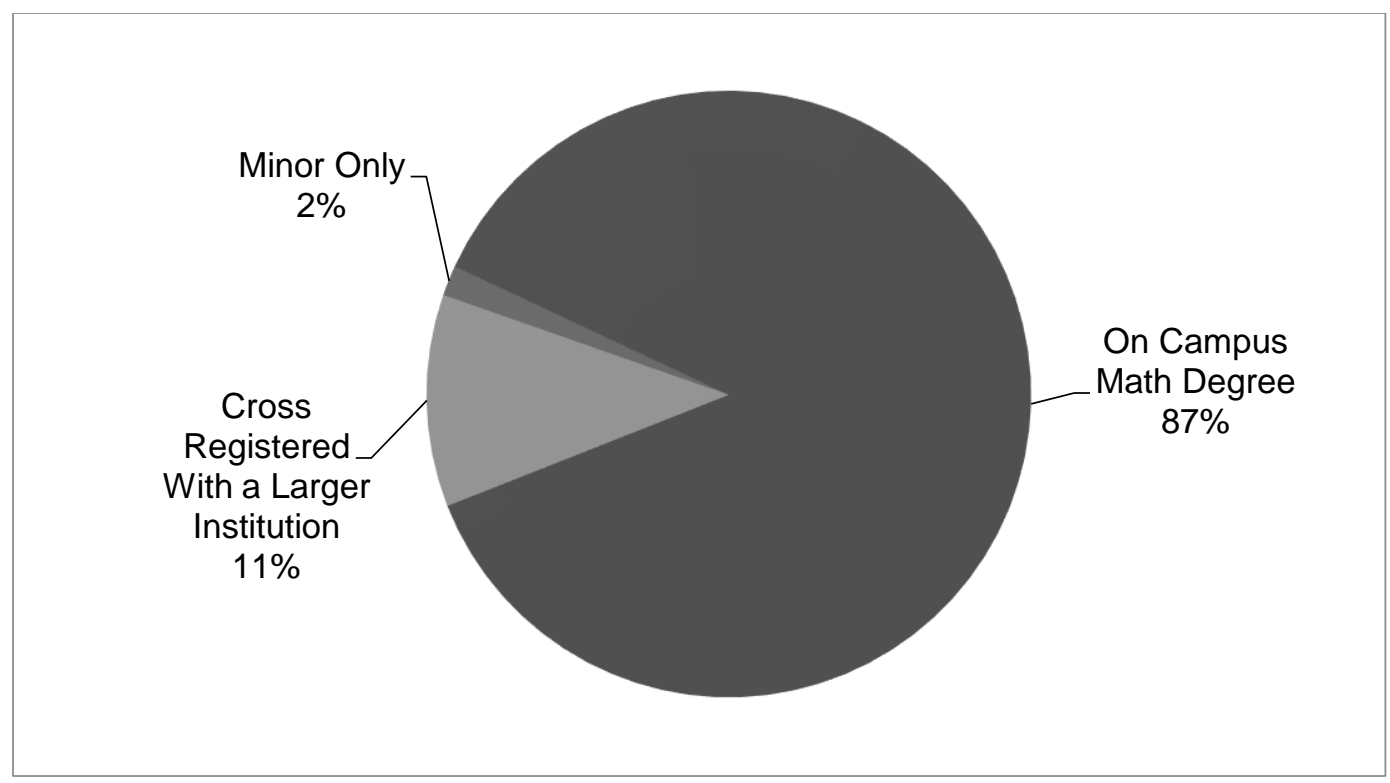

Figure 1. Types of mathematics programs offered by universities $(N=62)$.

Categories of analysis derived from our review of the relevant literature described earlier included: (a) admission prerequisites (including grade averages, mathematics prerequisites, English prerequisites); (b) streaming procedures for course enrolment; (c) types of remediation programs; (d) details about mathematics help centers (numbers, hours, and accessibility of online information); (e) availability of first-year mathematics courses for non-mathematics majors; and (f) and special access initiatives for female or Indigenous students.

The data collection process was standardized with the use of nominal and ratio variables where appropriate. Descriptive statistics (i.e., frequencies, means) were calculated where appropriate. For example, minimum entrance averages calculated using six secondary school course credits, total number of help centers, and total number of hours per week provided by each help center were recorded as numerical values. Given that all the mathematics departments offered more than one degree, the average minimum admission average for honours Bachelor of Science study was calculated for the department, rather than presenting each minimum admission average for each program.

When examining course streaming procedures, each university was either categorized as a university that streamed based on secondary school grade(s) or as a university that used secondary school grade(s) and placement tests to evaluate student readiness for first-year mathematics courses. Given that the literature review suggested that students who do well in secondary school English, as well as secondary school mathematics, also do well in post-secondary mathematics (Dame, 2012), each university's entrance prerequisite was reviewed to survey English proficiency requirements for admission to a mathematics degree.

Remediation programs were assessed on these three criteria (as applicable): (a) are remediation courses optional for students in a mathematics degree? (b) Do students receive a mathematics or non-mathematics credit for completing these remediation courses? and (c) Is there 
a fee for enrolling in these courses? Finally, binary values were used to indicate the availability of first-year mathematics courses for non-mathematics majors, and for special access or retention initiatives for women or Indigenous students.

It is important to note again that only publicly available web-based information was used. We did not limit the number of clicks that were required to find information. We did not restrict our searches to mathematics departmental websites exclusively. For example, in some instances mathematics help centers were housed in other university departments, and so our browsing led us to other university web pages. This also occurred when we were looking at course calendars that are often housed under registrar services. We recognize that some university and departmental websites may not be well maintained and up-to-date; therefore, some information was difficult to gather for some universities (i.e., information regarding remediation programs). The absence of information does not necessarily mean that universities do not provide such services, rather that we did not find it in our web-based search. For this reason, we provide illustrative examples only rather than university-specific data.

Relying exclusively on web-based information is a limitation of our research. However, our methods mirror the types of searches that might be undertaken by a potential student, school counselor, or parent, and thus our choice of methods does not, in our view, infringe on the potential usefulness of our findings.

\section{Results}

Our web-based analysis suggests that universities across Canada, and mathematics departments more specifically, have adopted similar standards for recruitment and supports for students (cf. Fenwick-Sehl, Fioroni, \& Lovric, 2009). While some notable differences were observed, relatively few universities seemed to stand out as pioneering in nature in that there were more similarities than differences.

\section{Admission Prerequisites (including admission averages)}

Admission considerations for a mathematics degree were mainly based on competitive secondary level grades. Minimum admission averages varied from one university to another and indeed between programs within each department.

We note that during our data collection, entrance averages were found for 57 of the 62 institutions under consideration. For departments that offered multiple programs, an average of the stated admission averages for all science programs offered was calculated for this analysis. Required admission averages ranged from $60 \%$ at Concordia University of Edmonton, Brandon University, and Canadian Mennonite University to $85 \%$ and above at McGill University, Queen's University, University of Alberta, University of Manitoba, and University of Waterloo. Course prerequisites were found to be fairly stable across universities with all universities requiring at least six university level high school courses (i.e., advanced university preparatory mathematics courses rather than courses intended for trades, technical studies, workplace, college level programming, etc.) for admission. However, the specific mathematics prerequisites varied from 
one university to another. The majority (87\%) of institutions required some sort of mathematics prerequisites, but only $19 \%$ of these universities asked for both high-school calculus (MCV) and advanced functions (MFH) as mandatory admission requirements (see Figure 2).

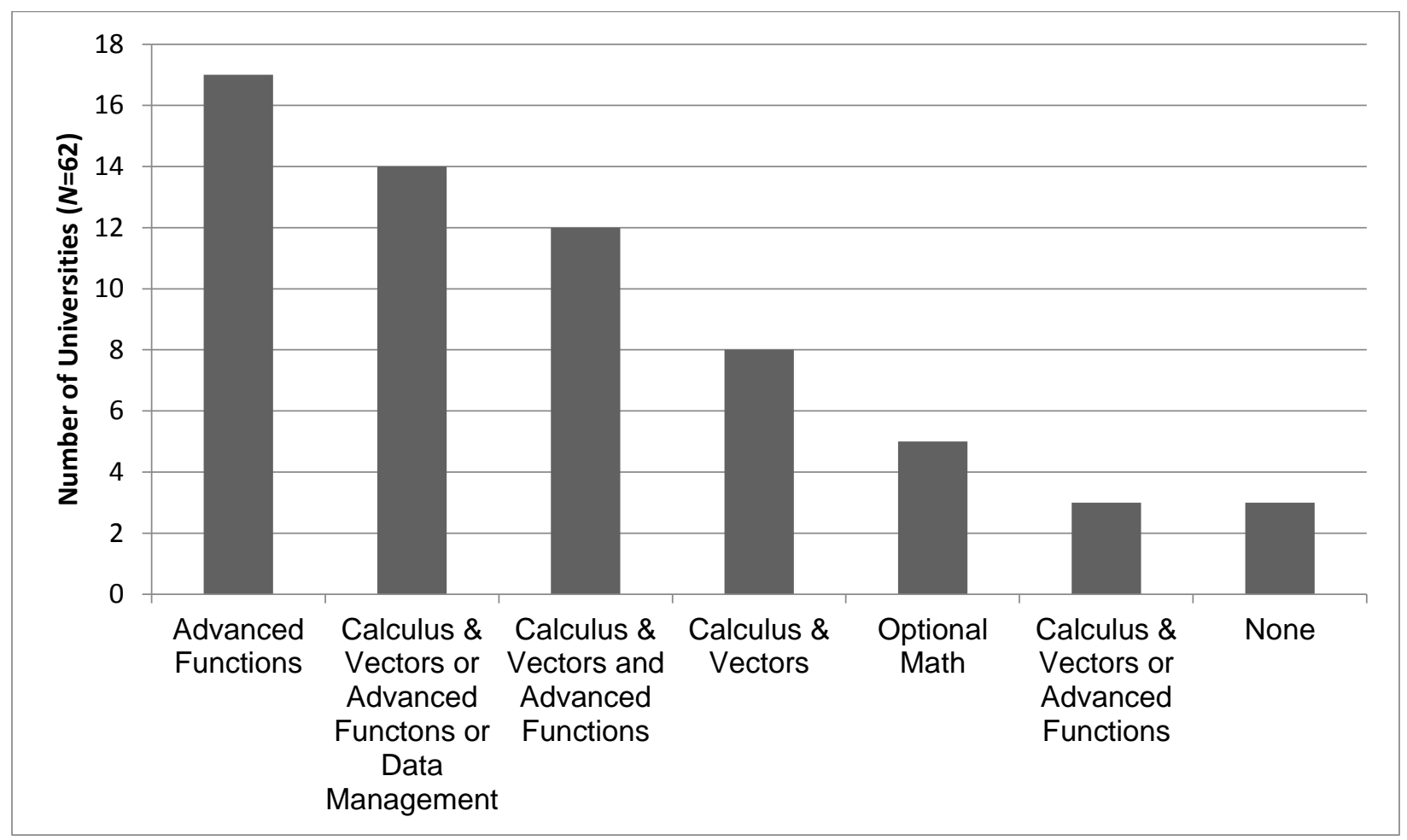

Figure 2. Mathematics prerequisites for admission.

With the exception of Athabasca University, Brock University, Carleton University and Ryerson University, all other universities also required the successful completion of Grade 12 English courses. In addition to Grade 12 English, the University of Waterloo was the only institution that also required all incoming students to take a compulsory in-person English proficiency test, regardless of the number of years studied at an English language high school.

\section{Streaming Procedures for Course Selection}

Efforts to stream students into first-year mathematics courses were found across all universities. Here, streaming refers to a process by which students are guided to the most appropriate first-level mathematics course for their degree of study. Secondary school averages, as a primary mechanism for streaming, were used by $48 \%$ of the universities. In addition to secondary school average, $52 \%$ of universities also used a placement test to stream students into their initial calculus courses, with the recommendation emerging from the outcomes of the placement test as optional in $19 \%$ of the departments of mathematics (see Figure 3). 


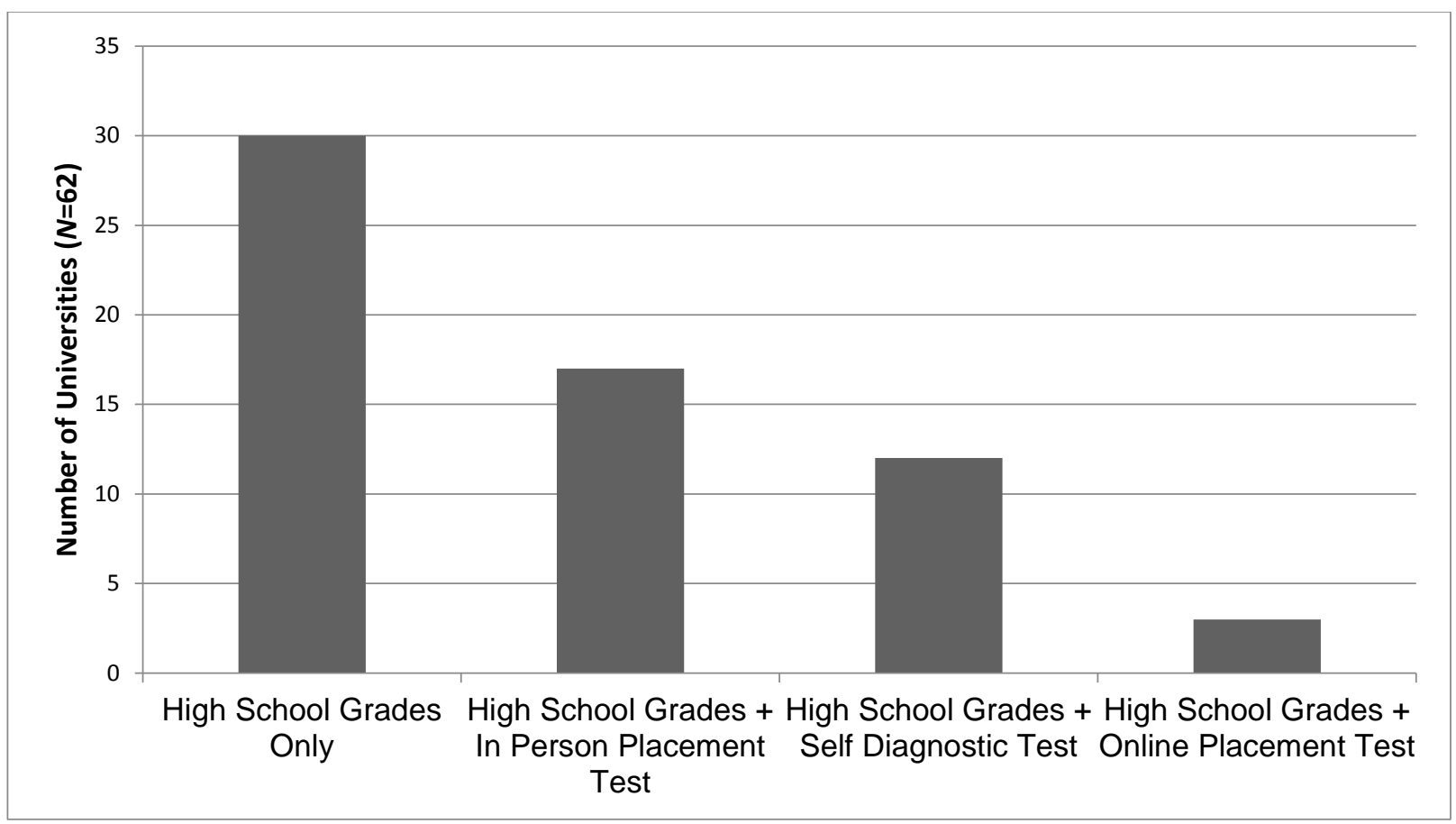

Figure 3. Comparison of methods of streaming between universities.

At Wilfrid Laurier University, for example, all students who wish to enroll in a first-year calculus course are required to write the Calculus Preparation Evaluation (CPE). The outcome of the CPE is intended to guide students into the correct first-year calculus course based on their CPE results as a proxy for their readiness. The CPE does not force students into a specific course. However, in order to enroll in MA103: Calculus I, an honours level first-year calculus course, a student must score $70 \%$ or higher on the CPE. The decision to make a score of $70 \%$ or higher as a requirement was based on an analysis of institutional data from the 2004/2005 through the 2006/2007 academic years, which showed that the majority of students who scored less than this threshold did not successfully complete MA103 (Wilfrid Laurier University, 2014).

\section{Types of Remediation Programs}

Most universities (77\%) offered remedial programming (e.g., course, online modules) for students who either did not have the prerequisites for mathematics programs or for students who did not meet minimum achievement requirements in the placement testing. Almost half of these remedial courses $(47 \%)$ were offered as optional courses to prepare students. Very few universities delivered remedial courses for non-mathematics elective credit (16\%) or for credit that could count towards a student's mathematics degree (18\%; see Figure 4). No university was found to offer these courses free of charge. 


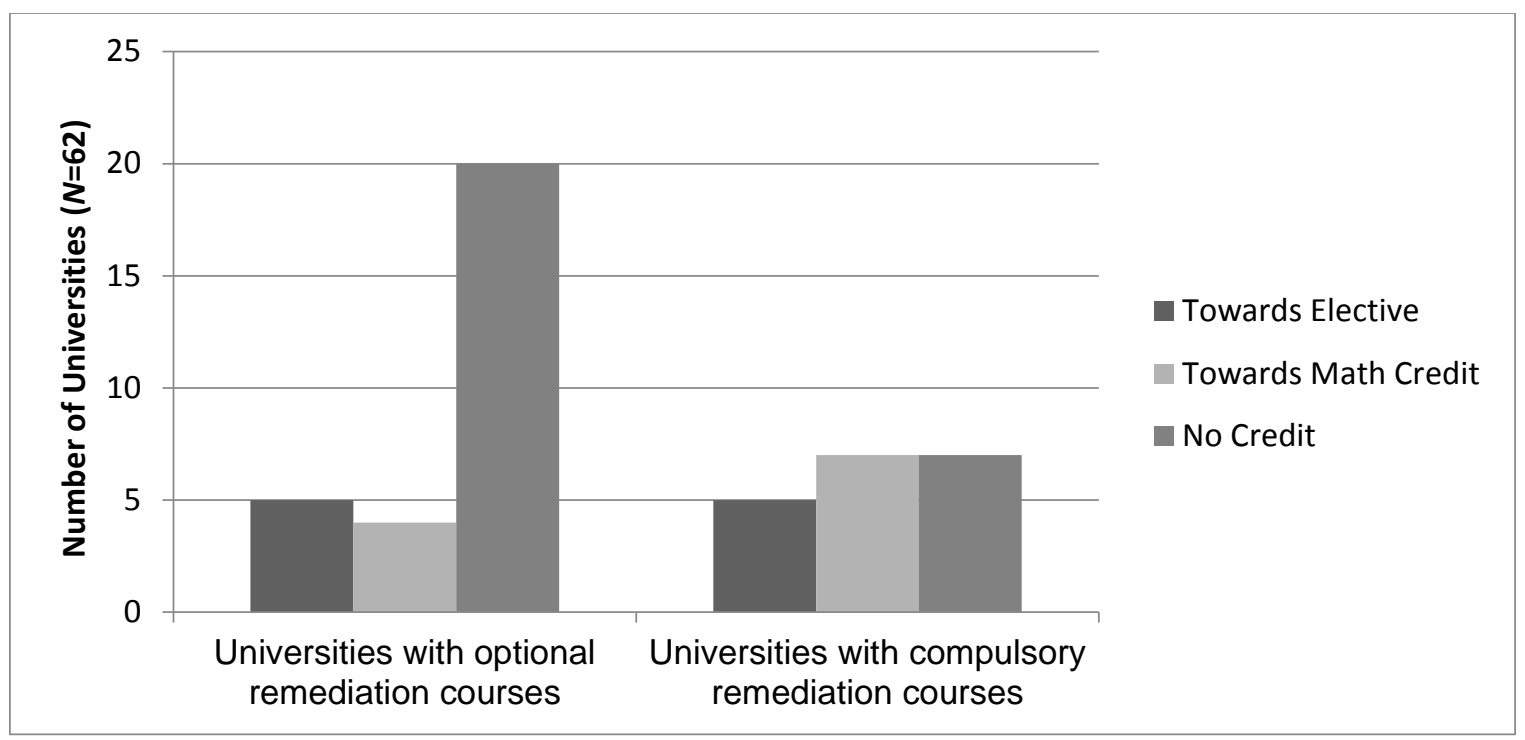

Figure 4. Types of remediation programs offered at Canadian universities.

We note that there were four entry-level, non-credit remedial mathematics courses offered at Lakehead University that appeared to be specifically targeted towards Indigenous students (Lakehead University, 2014b). Two of these courses were for Native Access Students and the other two courses were for the Native Nursing Entry Program (Lakehead University, 2014b).

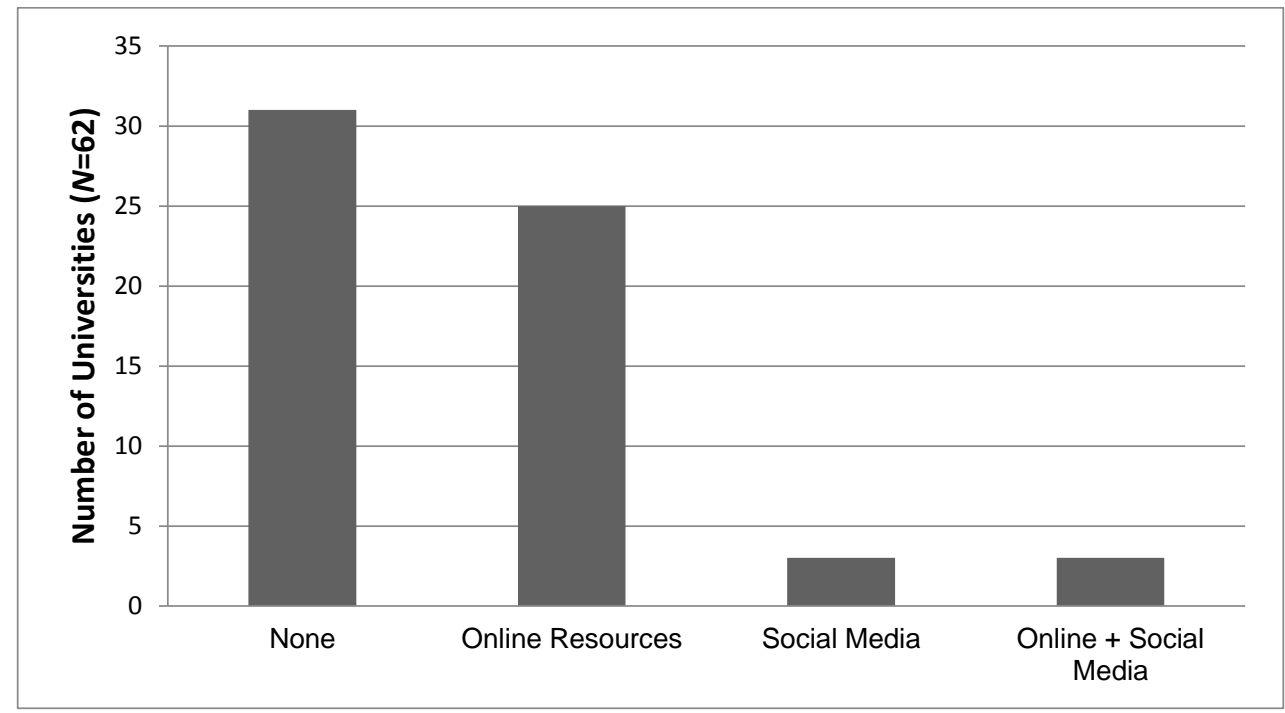

Figure 5. Breakdown of the types of electronic resources available to students.

\section{Mathematics Help Centres}

The majority of universities examined had mathematics help centers, with $66 \%$ having only one help center per campus, $11 \%$ having two help centers, and $11 \%$ having had greater than two help centers. Mathematics help centers were open to students for an average of 38 hours per week 
$(\max =109, \min =2, \mathrm{SD}=20.43)$. In addition to mathematics help centers, nearly half the universities $(45 \%)$ also provided links to online resources to support mathematics education; however, only a few universities (10\%) were found to use technology (e.g., social media, web-based videoconference services such as Skype etc.) to connect with students to deliver mathematics help remotely. For example, Lakehead University provided real-time mathematics assistance via the Internet using Skype. See Figure 5 for further breakdown of type of electronic resources available.

We also assessed how straightforward it was to locate information on the assistance resource(s) available by starting at each mathematics department's homepage and tracking the number of clicks required when locating help. We found that $40 \%$ of the institutions required two clicks to go from the mathematics homepage to the help center webpage and $32 \%$ required only one click (see Figure 6). Bishop's University was the only university that listed help center information directly on the homepage of its mathematics department.

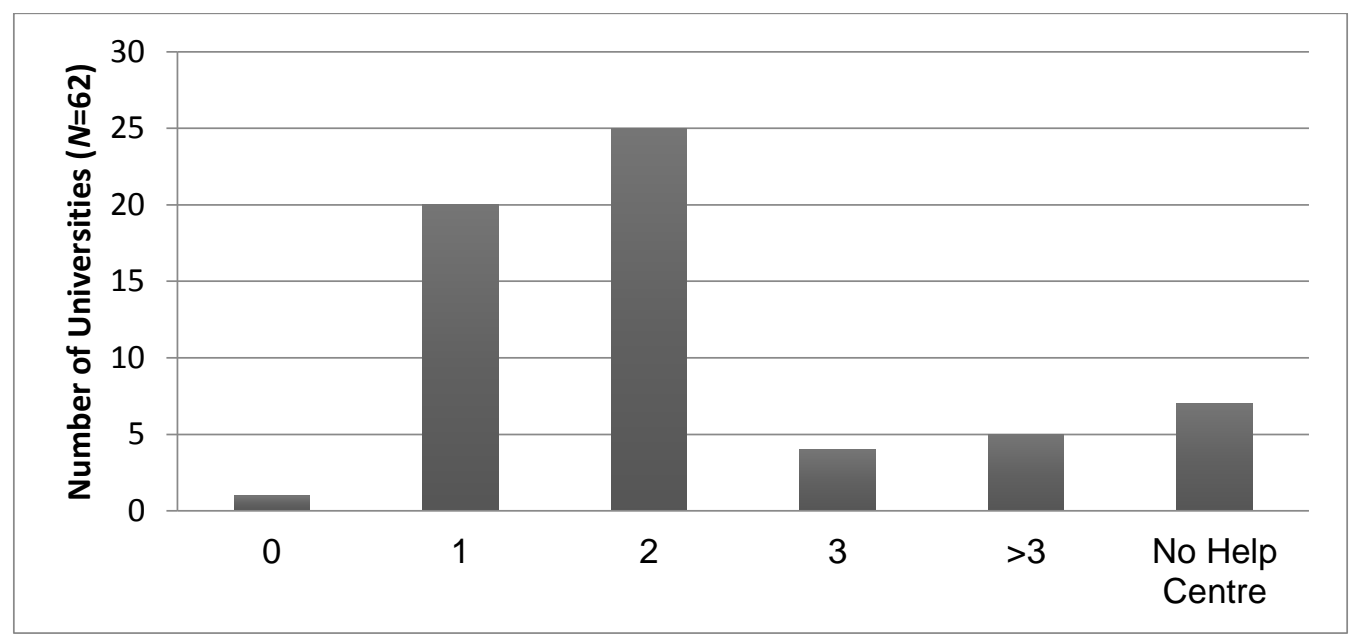

Figure 6. Number of clicks required to access information on mathematics help services starting at main mathematics homepage.

\section{Availability of First-year Mathematics Courses for Non-mathematics Majors}

We found that $37 \%$ of universities attempted to attract non-mathematics students by offering first-year mathematics courses that were specifically designed for them. There has been some suggestion that offerings of this nature are important for instilling basic mathematical literacy amongst Canadians (Dion, 2014). Courses that we identified appeared to be targeting students who did not have extensive previous mathematics knowledge. The primary aim of those courses was to promote student interest for mathematics by showing them the beauty and importance of mathematics in everyday life. One example is a course offered at Simon Fraser University in British Columbia entitled Math 197: Hitchhiker's Guide to Everyday Mathematics. The course description was as follows:

Should you buy a ticket for $6 / 49$ or Super 7 ? If you tested positive for a rare disease, what is the chance that you actually do have it? What are likely to be the consequences of moving to a single transferable vote voting system from a "first past the post" voting system? What 
is the connection between Chinese dragging noodles, E. coli bacteria and interest on your credit card? These are some of the questions we will be investigating in this course. We will also look into the use, misuse and abuse of mathematics in the media and advertisements. (Simon Fraser University, 2015)

The prerequisites for Math 197 at Simon Fraser University stated that the course could not be counted towards a mathematics degree and only grade 11 mathematics courses (or third year of post-secondary study) are required, which in Canada is the minimum level of mathematics study that students must take during secondary school.

\section{Women and Indigenous Students}

Aside from club-like structures or centers for female students pursing STEM-based studies within the university (e.g., Dalhousie University's Women in Technology Society [WiTS], University of Waterloo's Women in Mathematics [WIM]) none of the departments of mathematics at any of the universities were found to have any targeted admission or access strategies for women or Indigenous peoples.

\section{Discussion}

Our analysis of 62 Canadian English-speaking universities' departments of mathematics revealed more similarities than differences - despite the size or focus of the university. In addition to many universities requiring secondary school-level English, our results showed that many of the universities' minimum admission averages were approximately $72 \%$ (see Figure 2 ). The precise number of students admitted with a secondary average in the B range (i.e., at least $70 \%$ but less than $80 \%$ ) is unknown. Students admitted with secondary school mathematics grades in this range may be more likely to experience struggles in post-secondary mathematics (Dame, 2012; Dietsche, 2012; Faridhan et al., 2013; Orpwood et al., 2011). It may be that many students admitted into mathematics programs are underprepared for university level mathematics at the onset of their university studies.

Secondary school mathematics grades were used by approximately two-thirds of the universities as a mechanism for streaming students into their first mathematics courses in year one of their university studies. Some universities also use placement tests to stream students into appropriate mathematics courses. This may not be an effective way to promote student success. For example, the research suggests that secondary school mathematics grades are likely the best measure of future success, more so than placement tests (locally developed or otherwise) and more so than placement tests that do not have a mandatory streaming outcome (e.g., a minimum grade to gain access into a particular course) (Dame, 2012; Hailikari et al., 2008). Since many of these placement tests do not have mandatory outcomes in terms of placement, students may be less motivated to prepare and perform their best on these assessments. Universities may need to revisit admission and streaming mechanisms to better align practices with actual outcomes and with recommendations from the literature in order to support greater student success. 
The profile of the student who typically does well in post-secondary mathematics continues to be stable: high performance in secondary school, male, and STEM-focused (Hango, 2013a; Orpwood et al., 2011). Despite this stability of the typical mathematics student, the reality is that the profile of students attending post-secondary institutions has changed. With the exception of gender, students in post-secondary school mathematics classrooms are likely more diverse in their profiles and in their range of ability, which may account for the reports of lack of readiness to engage with advanced mathematical content (Dietsche, 2012; Strother et al., 2013).

Besides the changing demographics of students, we also note that current 21 st century students are of a digitally-reliant generation, and yet, very few universities used interactive applications to engage students in mathematical support. Many universities focused on delivering face-to-face on-campus mathematics help, and online resources were found to be second place supplementary material. Providing support through mathematics help centers is an excellent method to engage students in the learning process and results show that those students that use this support benefit academically (Dame, 2012; Dietsche, 2012). The number of mathematics centers and the number of hours face-to-face support is provided is important in that more hours and more centers could imply greater opportunities for student support. Our web-based review makes no claims on the quality of the support or student uptake.

The main challenge continues to be engaging students who need these services the most. Very few universities have successfully incorporated virtual support systems by providing help via social networking or interactive sites such as Facebook and Skype (i.e., Lakehead University). Within a course or even within departments, some instructors or institutions may initiate discussion boards using institutional-based learning management systems (e.g. Moodle, MyLearningSpace, Desire2Learn, WebCT, etc.). Our analysis did not consider such usages but rather focused on external cloud-based platforms that we surmise are highly relevant and in use by many postsecondary students. Additionally, no open discussion boards were found. We are aware of research in this area and note that extending support services into the virtual realm may (a) reach more students, (b) encourage more student participation through possible anonymity from class-mates as well as course instructor, and (c) connect to students in ways that are more current and relevant for students today (Hooper, Pollanen, \& Teismann, 2006). In addition, the use of these virtual tools may enable universities to provide an environment that creates a sense of community through the use of social and connective networks as well as an accessible service setting for student to obtain help, as well as help each other, in their mathematics courses. This sense of community may be lacking in the current environment where most first-year mathematics classes at most institutions likely have large class sizes. Although these online resources have the potential to improve student involvement, it appears that very few universities currently use such resources to support students enrolled in mathematics courses. One such reason is likely the challenge of text-based communication where symbols required for mathematical sciences are required.

The majority of remedial programs offered at the 62 universities were largely disconnected from degree requirements, even though studies show that this is a less effective approach for remediation (Charles A. Dana Center et al., 2012; Complete College America, 2012). This is likely due to remediation being viewed as extra for those who need it, and not a part of the post-secondary 
level degree requirements. The same studies state that remedial programs as part of the degree structure, rather than an add-on or as optional, are most effective. Consequently, the current way in which remediation is conceived of in universities should be re-evaluated since it may be that the way in which remediation is delivered disadvantages students.

The ease with which the student makes the transition from secondary school to postsecondary level education is one of the primary factors that develops their attitude toward mathematics. If students are unable to make a smooth shift from secondary school mathematics to university level mathematics, they may be more likely to struggle. Several universities developed remediation courses that were aimed to ease a student's transition into mathematics; however, many of these courses were offered as optional, not-for-credit and for a fee. As earlier studies suggest, offering optional non-credit courses are not effective due to the fact that these courses provide no incentives for students to seek extra help. Also, students often perceive that they have a heavy course load and have less time or have a scheduling conflict, and therefore do not take advantage of these courses. Thus, instead of having optional remediation courses, it is more effective to have courses that are integrated into the degree requirements. For that reason, universities should revise and develop courses that better suit the need of today's student demographic.

Male students are now outnumbered by female students in most fields of study in Canada, however, this does not hold true for mathematics programs (Ferguson, 2016; Hango, 2013b; Statistics Canada, 2011; University of Waterloo, 2018). Fewer females are studying mathematics. None of the universities studied in this research were found to have programs that specifically have targeted access initiatives for females to pursue mathematics as a career. Many universities had club-like structures for those women within the university system already and certainly these clubs may engage in outreach activities. This is very different than targeted access initiatives aimed specifically at women. Additionally, given the low numbers of females participating in university mathematics, the extent to which club-like structures (with or without outreach efforts) are effective is immediately brought into question. Consequently, it may not be altogether surprising that fewer female students are choosing mathematics as a discipline of study.

Some universities were found to offer courses that were specifically designed to attract non-mathematics majors. However, these courses also did not specifically target women; they targeted the student body as a whole. Recruitment practices at universities need close scrutiny if there is a genuine interest in seeing more women and Indigenous peoples studying mathematics. Some effort was seen at Lakehead University in terms of their remedial offerings for Indigenous students in mathematics and in some other curricular areas as well. However, these courses were not for credit.

As Dion (2014) points out, all post-secondary students should be encouraged to take a mathematics course during university in order to increase the general mathematical literacy of all university educated Canadians. More than half of the institutions did not offer such courses and this may be an area of opportunity for mathematics departments to consider. 


\section{Conclusion}

Given Canada's performance on the standardized testing of mathematics, it may be justifiable to assume the number of students who will experience challenges with post-secondary mathematics will grow, and women and Indigenous peoples will continue to be underrepresented. Indeed, little evidence was found across the universities we studied to suggest a tangible commitment to broadening access to mathematics for those student groups that are currently underrepresented in the discipline. A greater commitment to promoting success in university mathematics education is necessary and this may mean rethinking how to provide a mathematics education to today's postsecondary students rather than the typical mathematics student. This means reconsidering admission protocols, the relationship of remediation to the overall degree, retention efforts, and the way in which support is delivered to students (Fenwick-Sehl et al., 2009).

The universities that we studied in this research had remarkably homogeneous admission protocols and remedial programming (including access to mathematics help centers, and lack of virtual supports). If universities want to encourage student success in mathematics education and diversification of students more broadly, then new approaches may be necessary. Additionally, the approaches may vary across institutions. From an innovation and economic perspective, there may be an urgent imperative to engage in a Canada-wide mathematics education reform. This will require federal and provincial investment in both teaching development and research related to post-secondary success in mathematics.

Several research questions have arisen from this preliminary study of universities and their departments of mathematics: (a) Is there a growing trend in students being underprepared to study mathematics? (b) How can universities respond to such trends? and (c) Are there attrition concerns mounting in mathematics degrees? Analyzing these questions from a multi-institution perspective would be important in further defining the landscape of mathematics education across Canadian universities.

\section{References}

Alphonso, C. (2013). Canada's falling math rankings renews push for national standards. The Globe and Mail. Retrieved from http://www.theglobeandmail.com/news/ national/education/canadas-falling-math-rankings-renews-push-for-nationalstandards/article $15755434 /$

Charles A. Dana Center, Complete College America Inc., Education Commission of the States, $\&$ Jobs for the Future. (2012). Core principles for transforming remedial education: A joint statement. Retrieved from https://www.jff.org/resources/core-principles-transformingremedial-education-joint-statement/

Complete College America. (2012). Remediation: Higher education's bridge to nowhere. Retrieved from https://www.insidehighered.com/sites/default/server files/files/CCA\%20 Remediation\%20ES\%20FINAL.pdf

Conference Board of Canada. (2014). Graduates in science, math, computer science, and engineering. Retrieved from http://www.conferenceboard.ca/hcp/provincial/education/ sciencegrads.aspx 
Dame, L. (2012). Student readiness, engagement and success in entry level undergraduate mathematics courses (Unpublished doctoral dissertation). University of Victoria, Victoria, BC.

Dietsche, P. (2012). Use of campus support services by Ontario college students. Canadian Journal of Higher Education, 42(3), 65-92.

Dion, N. (2014). HEQCO report on numeracy skills. Toronto, ON: Higher Education Quality Council of Ontario. Retrieved from http://www.heqco.ca/SiteCollectionDocuments/ Numeracy\%20ENG.pdf

Dooley, M., Payne, A. A., Steffler, M., \& Wagner, J. (2016). Understanding the STEM path through high school and into university programs. Toronto, ON: Higher Education Quality Council of Ontario. Retrieved from http://www.heqco.ca/SiteCollectionDocuments/ High\%20School\%20STEM-ENG.pdf

Faridhan, Y. E., Loch, B., \& Walker, L. (2013). Improving retention in first-year mathematics using learning analytics. In H. Carter, M. Gosper \& J. Hedberg (Eds.), Electric dreams. Proceedings ascilite 2013 Sydney (pp. 278-282). Sydney, Australia: Proceedings ascilite Sydney 2013.

Fenwick-Sehl, L., Fioroni, M., \& Lovric, M. (2009). Recruitment and retention of mathematics students in Canadian universities. International Journal of Mathematical Education in Science and Technology, 40(1), 27-41.

Ferguson, S. J. (2016). Women in Canada: A Gender-based Statistical Report-Women and Education: Qualifications, Skills and Technology. Ottawa, ON: Minister of Industry, Statistics Canada. Retrieved from https://www150.statcan.gc.ca/n1/en/pub/89-503x/2015001/article/14640-eng.pdf?st=sxBH7SIS

Hagedorn, L. S., Siadat, M. V., Fogel, S. F., Nora, A., \& Pascarella, E. T. (1999). Success in mathematics: Comparisons between remedial and nonremedial first-year college students. Research in Higher Education, 40(3), 261-284.

Hailikari, T., Nevgi, A., \& Komulainen, E. (2008). Academic self-beliefs and prior knowledge as predictors of student achievement in mathematics: A structural model. Educational Psychology, 28(1), 59-71.

Hall, J. (2012). Gender issues in mathematics: An Ontario perspective. Journal of Teaching and Learning, 8(1), 59-72.

Hango, D. (2013a). Ability in mathematics and science at age 15 and program choice in university: Differences by gender. Ottawa, ON: Tourism and Centre for Education Statistics Division, Ministry of Industry.

Hango, D. (2013b). Gender differences in science, technology, engineering, mathematics and computer science (STEM) programs at university. Ottawa, ON: Ministry of Industry.

Hooper, J., Pollanen, M., \& Teismann, H. (2006). Effective online office hours in the mathematical sciences. MERLOT Journal of Online Learning and Teaching, 2(3), 187-194.

Kuh, G. D., Kinzie, J., Buckley, J. A., Bridges, B. K., \& Hayek, J. C. (2007). Piecing together the student success puzzle: Research, propositions and recommendations. ASHE Higher Education Report (Vol. 5). San Francisco, CA: Jossey-Bass.

Lakehead University. (2014a). Mathematics 1130: Math Skills for Native Access Students I. Retrieved from http://timetable.lakeheadu.ca/scripts/return.course.description.php? $\mathrm{c}=$ MATH\&cn $=1130$

Lakehead University. (2014b). Mathematics 1135: Math for NNEP Students. Retrieved from http://navigator.lakeheadu.ca/Catalog/ViewCatalog.aspx?pageid=viewcatalog\&topicgroupid $=8228$ \&entitytype=CID\&entitycode=Mathematics +1135 
Let's Talk Science. (2013). Spotlight on science learning: The high cost of dropping science and math. Retrieved from http://letstalkscience.ca/News-Events/ArticleId/9/spotlight-on-sciencelearning-the-high-cost-of-dropping-science-and-math

MacDonald, M. (2014, June/July). Professors debate the best way to teach math. University Affairs. Retrieved from https://www.universityaffairs.ca/features/feature-article/how-toteach-math

Mji, A., \& Mwambakana, J. (2008). Is mathematics anxiety a factor? First-year university students provide answers. African Education Review, 5(1), 20-29.

Moffatt, M., \& Rasmussen, H. (2016). Big idea: A Canada-wide transformation of numeracy skills. Canada2020. Retrieved from http://canada2020.ca/numeracy/

Nahornick, A. (2016). Math matters: Comparison of the mathematics requirements for bachelor of arts and bachelor of science degrees in Canada. Canadian Journal of Higher Education, 46(1), 109-120.

O'Grady, K., Deussing, M., Scerbina, T., Fung, K., \& Muhe, N. (2013). Measuring up: Canadian results of the OECD PISA Study. The performance of Canada's youth in mathematics, reading and science 2012. First results for Canadians aged 15. Ottawa, ON: Council of Ministers of Education.

Organisation for Economic Co-operation and Development. (2012). PISA 2015 Results. Retrieved from http://www.pisa.oecd.org/

Orpwood, G., Schollen, L., Leek, G., Marinelli-Henriques, P., \& Assiri, H. (2011).College mathematics project 2010: Final report. North York, ON: Seneca College of Applied Arts and Technology.

Ovsey, D. (2013). Business leaders ringing alarm bell on falling literacy, numeracy rates; call for improvements to education. Financial Post. Retrieved from http://business.financialpost.com/2013/11/28/business-leaders-ringing-alarm-bell-on-fallingliteracy-numeracy-rates-call-for-improvements-to-education/

Perkin, G., \& Bamforth, S. (2011). A variety of approaches to the provision of mathematics help for first-year engineering undergraduates. International Journal of Electrical Engineering Education, 48(1), 79-91.

Pidgeon, M., Archibald, J., \& Hawkey, C. (2014). Relationships matter: Supporting Aboriginal graduate students in British Columbia. Canadian Journal of Higher Education, 14(1), 1-21.

Sands, A. (2014). Slipping math scores don't equal a crisis, says math conference panel. Edmonton Journal.

Scerbina, T., Sukovski, K., Duclos, É., Rainville, B., Santilli, D., Hango, D., . . \& M Marmen, L. (2013). Skills in Canada: First results from the Programme for the International Assessment of Adult Competencies (PIAAC). Ottawa, ON: Minister of Industry, Statistics Canada.

Silva, E., \& White, T. (2013). Pathways to improvement: Using psychological strategies to help college students master developmental math. Stanford, CA: Carnegie Foundation for the Advancement of Teaching.

Simon Fraser University. (2014). Math 197: Hitchhiker's Guide to Everyday Mathematics. Retrieved from https://www.sfu.ca/students/calendar/2014/spring/ courses/math.html

Statistics Canada. (2005). The Adult Literacy and Life Skills Survey. Ottawa, ON: Government of Canada.

Statistics Canada. (2011). National Household Survey. Ottawa, ON: Government of Canada. Retrieved from https://www12.statcan.gc.ca/nhs-enm/2011/dp-pd/prof/index.cfm?Lang=E

Stinebrickner, R., \& Stinebrickner, T. R. (2014). A major in science? Initial beliefs and final outcomes for college major and dropout. Review of Economic Studies, 81(1), 426-472. 
Strother, S., Campen, J. V., \& Grunow, A. (2013). Community college pathways: 2011-2012 Descriptive report. Stanford, CA: Carnegie Foundation for the Advancement of Teaching. Retrieved from https://www.carnegiefoundation.org/wp-content/uploads/2014/09/ CCP Descriptive Report Year 1.pdf

University of Waterloo. (2018). Women in mathematics: Representation by gender. Retrieved from https://uwaterloo.ca/women-in-mathematics/representation-gender

Wilfrid Laurier University. (2014). Statistics for the Calculus Preparatory Evaluation (CPE). Retrieved from https://students.wlu.ca/registration-and-finances/registration-guide/beforeyou-register/calculus-preparation-evaluation.html 